\title{
Role of Oxygen Radicals in the Microcirculatory Manifestations of Postischemic Injury
}

\author{
M.D. Menger, H.-A. Lehr, and K. Messmer \\ Institut für Chirurgische Forschung, Klinikum Großhadern, Ludwig-Maximilians-Universität München
}

Klin Wochenschr (1991) 69:1050-1055

Figure 2 in the above article should be replaced by the following diagram:

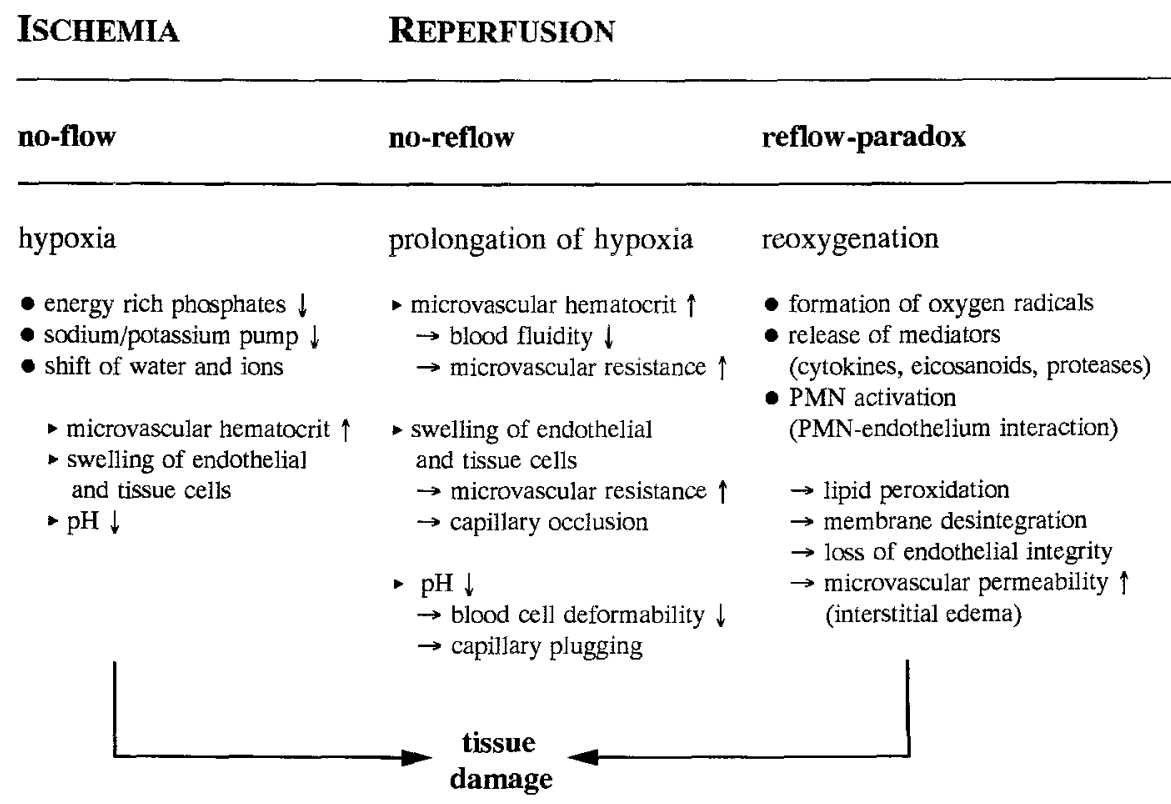

\section{ISCHEMIC INJURY REPERFUSION INJURY}

Fig. 2. Pathomechanisms of microvascular and cellular injury in ischemia-reperfusion, including the no-flow state during ischemia, as well as no-reflow and reflowparadox during postischemic reperfusion 